\title{
Changes in attitudes toward psychiatry with introduction of a new curriculum: experiences of a Sri Lankan medical school
}

Asiri Rodrigo, Chamara Wijesinghe, KALA Kuruppuarachchi

\section{Background}

A Sri Lankan university recently changed its medical undergraduate curriculum by including a multifaceted psychiatry clerkship for final year students.

Aims

We investigated the effect of introducing an eightweek clinical rotation on career choice and attitudes of medical students towards psychiatry as a discipline. Method

One hundred medical students completed the Attitudes Towards Psychiatry (ATP-30) questionnaire before and after the final year psychiatry clerkship.
Results

This study showed favourable improvements in the ATP-30 score following exposure to the professorial clerkship. Significant increase were noted in the desire to pursue a career in psychiatry.

\section{Conclusion}

Exposure to a psychiatry clerkship in the final year could improve the attitudes of medical students towards psychiatry.

SL J Psychiatry 2012; 3 (1):14-16

\section{Introduction}

Interest in psychiatry among medical undergraduates has remained low despite recent developments in the discipline (1-6). The declining interest in psychiatry among medical students and junior doctors has been of concern in both developed and developing countries (1-7). The percentage of medical students pursuing psychiatry as post-graduates has been gradually declining over the past 50 years and psychiatry remains one of the least favoured medical specialties (8). As a result there is a global shortage of psychiatrists; this is more acute in developing countries $(1,8,9)$. A recent survey has revealed that only $1.8 \%$ of Sri Lankan doctors chose psychiatry as a career (10). Sri Lanka has an acute shortage of psychiatrists with an average of one psychiatrist for every 500,000 people (10).

It is also noteworthy that persons with mental illnesses have been stigmatised by society through the ages. Patients with psychiatric ailments being depicted as violent, unpredictable and dangerous have contributed to this stigma and negative attitude (11). These negative attitudes towards the mentally ill patients have been reported among medical students $(1,3-7)$. When these individuals become practicing medical professionals these attitudes not only influence future career options but could also affect the care and management of patients with mental illnesses as many who do not specialise in psychiatry are likely to have to deal with patients with psychiatric problems some time during their career $(4,12)$. Fernando et al reported a high level of stigma towards mental illness among medical students at a Sri Lankan university (13).

Attitudes towards psychiatry and a career choice in psychiatry appear to have a multifactorial determination including demographics, social variables, personality and concern for the mentally ill $(1,4,8,14,15)$. A medical undergraduate's experience of psychiatry remains the most frequently cited or highest ranked influence on career choice $(14,15)$. While many studies indicate that increased exposure to psychiatry at medical school has a favourable influence on attitudes towards psychiatry and a career choice of the discipline, others imply that such exposure could be counterproductive or have a minimal effect $(1,3,6,7,14-17)$.

Psychiatry has gained an increasing importance in medical undergraduate curricula around the world in the last few decades (18). In keeping with this trend, a medical school in Sri Lanka revised its curriculum in 2008 allocating more time for the teaching of psychiatry through lectures, small group discussions and problem based learning. Psychiatry was also incorporated into the final year medical curriculum with an eightweek professorial clerkship that attempted to provide a multifaceted exposure in the subject to medical students. During the eight-week rotation they are exposed to acute in-patient psychiatry, child psychiatry, community psychiatry and addiction medicine. Students also have a two-week clinical attachment in psychiatry in their third year.

\section{Methods}

We investigated the effect of introducing an eight-week clinical rotation in the final year on career choice and attitudes of medical students towards psychiatry.

Final year medical students in the professorial rotation in psychiatry participated in the study. The Attitude Towards Psychiatry 30 (ATP 30) was offered to all students $(n=100)$ on the first and last days of the professorial clerkship in psychiatry.

ATP 30 is a 5-point Likert-type scale designed and validated by Burra et al (19). The scale consists of 
30 positively and negatively phrased items that measure the strength of the respondent's attitude to various aspects of psychiatry. The score of each positively phrased item is converted by subtracting it from 6 . The ATP score is the sum of the total scores for positive and negative phrased items. A high score on the scale indicates a positive attitude towards psychiatry (maximum $=150$, minimum=30, logical neutral point $=90$ ).

Students were informed that they could chose not to participate in the study. The questionnaires did not include any identifying information and students were asked to drop the folded questionnaires into a designated box, whether completed, partially completed, or not filled out at all, ensuring the students' anonymity.

The data obtained before and after the clerkship were compared using the Wilcoxon test and SPSS version 11 software.

\section{Results}

One hundred students were invited to participate in the study. At the beginning of the clerkship $91(91 \%)$ questionnaires were returned. The corresponding figure at the end of clerkship was $93 \%$.

The responses in the ATP 30 questionnaire were simplified by combining 'strongly agree' and 'agree' to form the 'agree' category and similarly the 'strongly disagree' and 'disagree' responses were combined into the 'disagree' category. The average pre-clerkship ATP-30 score was $100(\mathrm{SD}=8.9)$ and 12 students $(14.1 \%)$ scored below the neutral point (90). The average postclerkship score was $110.8(\mathrm{SD}=8.6)$ and only one student $(1.1 \%)$ scored below 90 . The difference in mean score, before and after the clerkship was not statistically significant $(\mathrm{p}=0.52)$. However 5 out of 30 items showed a statistically significant favourable difference following the 8 -week clerkship (table 1). None of the items showed a change in the negative direction.

\section{Discussion}

Students in this study showed a positive attitude towards psychiatry at the beginning of the professorial clerkship possibly due to the subject being introduced during the first four years with lectures, small group discussions, problem based learning and a short clinical attachment during the third year.

Although the ATP 30 scores recorded were comparable to previous studies conducted elsewhere, direct comparisons were difficult due to differences in the methodologies of the studies and the level of training of the participants.

This study showed a near three-fold increase in the likelihood of pursuing a career in psychiatry from $9.4 \%$ to $25.8 \%$. Similar improvements have been recorded following eight-week clinical attachments in both developed and developing countries $(3,4,6,7)$

Several previous studies have shown a dissonance between favourable attitudes and the intention to choose psychiatry as a future career $(2,14,15)$. This study however indicated no such disparity.

A significant improvement of attitudes was seen in five items which addressed different aspects ranging from choice of post-graduate career to awareness of available effective treatment and an increase in the holistic understanding of a patient. The latter would be advantageous in a primary care setting in Sri Lanka where many psychiatric disorders may present in the form of physical complaints. The finding that awareness of effective treatment modalities increased following the clerkship was also encouraging. It suggests that these medical graduates could guide their patients to seek medical assistance for psychiatric ailments in a culture that tends resort to expensive and often ineffective traditional healing rituals (20).

It has been demonstrated that favourable attitudes gained soon after exposure to a clerkship in psychiatry decline with time $(17,21,22)$. Therefore the increase in the ATP 30 scores needs to be interpreted with caution.

This study recorded a high response rate when compared to most other similar studies. Although students may

\begin{tabular}{|c|c|c|c|c|c|c|}
\hline & $\begin{array}{l}\text { Pre- } \\
\text { clerkship } \\
\text { Agree }\end{array}$ & $\begin{array}{l}\text { Pre- } \\
\text { clerkship } \\
\text { Disgree }\end{array}$ & $\begin{array}{l}\text { Post- } \\
\text { clerkship } \\
\text { Agree }\end{array}$ & $\begin{array}{l}\text { Post- } \\
\text { clerkship } \\
\text { Disagree }\end{array}$ & $\begin{array}{l}\text { Z- } \\
\text { score }\end{array}$ & $\begin{array}{l}P \\
\text { value }\end{array}$ \\
\hline I would like to be a psychiatrist & $9.4 \%$ & $41.1 \%$ & $25.8 \%$ & $27.9 \%$ & 2.651 & 0.009 \\
\hline $\begin{array}{l}\text { Psychiatric teaching increases our understanding of } \\
\text { medical and surgical patients }\end{array}$ & $23.5 \%$ & $51.7 \%$ & $41.9 \%$ & $31.1 \%$ & 2.447 & 0.014 \\
\hline $\begin{array}{l}\text { If I were asked what I considered to be the three } \\
\text { most exciting medical specialities psychiatry would be } \\
\text { excluded }\end{array}$ & $45.8 \%$ & $18.8 \%$ & $30.1 \%$ & $50.5 \%$ & 2.014 & 0.036 \\
\hline $\begin{array}{l}\text { These days psychiatry is the most important part of the } \\
\text { curriculum in medical school }\end{array}$ & $18.8 \%$ & $58.8 \%$ & $35.4 \%$ & $35.4 \%$ & 2.318 & 0.016 \\
\hline $\begin{array}{l}\text { In recent years psychiatric treatment has become quite } \\
\text { effective }\end{array}$ & $71.7 \%$ & $15.3 \%$ & $84.9 \%$ & $8.6 \%$ & 1.962 & 0.04 \\
\hline
\end{tabular}


have felt obliged to participate, it is unlikely that this fact contributed greatly to the high response rate as anonymity was strictly maintained to the extent of not collecting any demographic data including gender. The students were also aware that the study data would not be analysed prior to their final year examination. The possible social desirability bias, in terms of obligation to participate, may be ascertained in future studies by the use of the social desirability scale.

The positive findings of this study would be encouraging for other Sri Lankan medical schools which have also recently introduced psychiatry clerkships in their final year of undergraduate training.

Replicating this study with improvements at the same medical school and conducting similar studies at other universities could yield more useful information and assist in improving the quality of undergraduate training in psychiatry in Sri Lanka.

\section{Declaration of interest}

Authors are academic staff members of the university where the study was conducted but received no financial assistance for conducting this study

\begin{tabular}{|l|}
\hline Asiri Rodrigo, Lecturer \\
Chamara Wijesinghe, Lecturer \\
KALA Kuruppuarachchi, Professor of Psychiatry \\
Department of Psychiatry, Faculty of Medicine, \\
University of Kelaniya, Sri Lanka \\
Corresponding author \\
Asiri Rodrigo \\
E mail: asirir2000@yahoo.com \\
\end{tabular}

\section{References}

1. Lunn B. Recruitment into psychiatry: An International challenge. Australian and New Zealand Journal of Psychiatry. 2011; 45(10):805-807

2. Pidd S. Recruiting and retaining psychiatrists. Advances in Psychiatric Treatment. 2003;9:405 - 411.

3. Reddy JP, Tan SM, Azmi MT, Shaharom MH, Rosdinom $\mathrm{R}$, Maniam T, et al. The effect of a clinical posting in psychiatry on the attitudes of medical students towards psychiatry and mental illness in a Malaysian medical school. Annals of Academy of Medicine Singapore. 2005;34 (8):505-510.

4. Bulbena A, Pailhez G, Coll J, Balon R. Changes in the attitudes towards psychiatry among Spanish medical students during training in psychiatry. European Journal of Psychiatry. 2005; 19 (2):79-87

5. Malhi GS, Parker GB, Parker $K$ et al. Attitudes toward psychiatry among students entering medical school. Acta Psychiatrica Scandinavica. 2003; 107(6):424- 429.

6. Ndetei DM, Khasakhala L, Ongecha-Owuor F, et al. Attitudes Toward Psychiatry: A Survey of Medical Students at the University of Nairobi, Kenya. Academic Psychiatry. 2008;32(2):154-159.
7. Niaz U, Hassan S, Hussain H, et al: Attitudes toward psychiatry in pre-clinical and post-clinical clerkships in different medical colleges of Karachi. Pakistan Journal of Medical Sciences. 2003; 19 (14):253-263

8. Goldacre, M.J., Turner, G., Fazel S., et al. Career choices for psychiatry: national surveys of graduates of 1974-2000 from UK medical schools. British Journal of Psychiatry. 2005; 186:158-164

9. Patel V. The future of psychiatry in low- and middle-income countries. Psychological Medicine 2009 (11);39:1759-1762.

10. Kuruppuarachchi KALA. 2007. Tomorrow's Doctors: Training and Attitudes. Paper presented at; The 3rd International Conference of South Asian Federation of Psychiatric Associations; 2007 November 03; Kalutara, Sri Lanka.

11. Byrne P. Stigma of mental illness and ways of diminishing it. Advances in Psychiatric Treatment 2000;6, 65-72.

12. Alexander DA, Eagles JM. Changes in attitudes towards psychiatry among medical students: correlation of attitude shift with academic performance. Medical Education 1990; 24 (5): 452-460.

13. Fernando SM, Deane FP, McLeod HJ. Sri Lankan doctors' and medical undergraduates' attitudes towards mental illness. Social Psychiatry and Psychiatric Epidemiology 2010;45 (7):733-739.

14. Shah P, Brown T, Eagles J. Choosing psychiatry: factors influencing career choice among foundation doctors in Scotland. In: Brown T, Eagles J, eds. Teaching psychiatry to undergraduates. London: RCPsych Publications, 2011:255263.

15. Brown T, Addie K, Eagles J. Recruitment into psychiatry: views of consultants in Scotland. The Psychiatrist 2007; 31:411-413.

16. Balon R, Franchini GR, Freeman PS, et al. Medical students' attitudes and views of psychiatry: 15 years later. Academic Psychiatry 1999; 23 (1):30-36.

17. Baxter H, Singh SP, Standen P, Duggan C. The attitudes of 'tomorrow's doctors' towards mental illness and psychiatry: changes during the final undergraduate year. Medical Education. 2001; 35 (4):381-383.

18. Rao NR, Meinzer AE, Manley M, Chagwedera I. International medical students' career choice, attitudes toward psychiatry, and emigration to the United States examples from India and Zimbabwe. Academic Psychiatry 1998; 22 (2): 117-126.

19. Burra P, Kalin R, Leichner P, et al. The ATP 30: a scale for measuring medical students' attitudes to psychiatry. Medical Education 1982. 16 (1); 31-38.

20. Wolffers I. Illness behaviour in Sri Lanka: Results of a survey in two Sinhalese communities. Social Science and Medicine 1988; 27(5): 545-552.

21. Sivakumara K, Wilkinson G, Toon BK, Greer S. Attitudes to psychiatry in doctors at the end of their first post-graduate year: two-year follow-up of a cohort of medical students. Psychological Medicine 1986; 16 (2):457-460.

22. Maidment R, Livingston G, Katona M, Katona C. Carry on shrinking: career intentions and attitudes to psychiatry of prospective medical students. The Psychiatrist 2003; 27 : $30-32$. 